\title{
Three-Point Bending of Heat-Treatable Aluminum Alloys: Influence of Microstructure and Texture on Bendability and Fracture Behavior
}

\author{
IDA WESTERMANN, KNUT ERIK SNILSBERG, ZEINAB SHARIFI, \\ ODD STURE HOPPERSTAD, KNUT MARTHINSEN, and BJØRN HOLMEDAL
}

\begin{abstract}
Three-point bending tests of extruded aluminum alloys showed lower bendability when the bending axis is aligned with the extrusion direction compared to the transverse direction. In the present work, three different microstructures of a commercial AA7108 aluminum alloy were studied with respect to mechanical properties, texture, constituent particles, and crack propagation. The three different microstructures were an as-cast and homogenized material, a fibrous extruded material, and a cold rolled and recrystallized material. While the mechanical properties in tension are more or less the same for the three materials, the bendability is strongly dependent on the microstructure and the global alignment of constituent particles. The as-cast and homogenized material shows poor bendability due to large grains and constituent particles on the grain boundaries, which leads to decohesion and premature failure. The response of both the fibrous and the recrystallized materials depends on the direction of the bending axis. A strong fiber texture is found to influence the bendability by initiation of shear bands. The crucial fracture mechanism, however, seems to be the global alignment of constituent particles, which is inherited from the deformation process.
\end{abstract}

DOI: $10.1007 / \mathrm{s} 11661-011-0768-\mathrm{y}$

(C) The Author(s) 2011. This article is published with open access at Springerlink.com

\section{INTRODUCTION}

Aluminum alloys in the form of rolled sheets and extruded profiles intended for use in the automotive industry should possess an appropriate combination of strength and ductility. Sheets or profiles are typically formed into final shapes such as body panels or bumper beams by cold deformation. Hence, the bendability of the material is of great importance in fabrication as well as in use, where the ductility is required for optimal energy absorption. Uniaxial tensile testing is often used to determine the mechanical properties of metals. However, this type of test does not always give a good description of the deformation mode experienced by a component. In this case, the three-point bending test is a suitable method for describing the mechanical properties. The bendability is defined as the ratio between the minimum bending radius and the thickness of the test specimen without fracture occurring. ${ }^{[1-4]}$ In 1960, Datsko and Yang ${ }^{[1]}$ came up with a simple relationship between bendability and the reduction in area obtained by tensile testing. This

IDA WESTERMANN, Postdoctoral Candidate, and ODD STURE HOPPERSTAD, Professor, are with the Structural Impact Laboratory (SIMLab), Centre for Research-Based Innovation, 7491 Trondheim, Norway and is also with the Department of Structural Engineering, Norwegian University of Science and Technology, 7491 Trondheim, Norway. Contact e-mail: ida.westermann@ntnu.no KNUT ERIK SNILSBERG and ZEINAB SHARIFI, Master Students, KNUT MARTHINSEN and BJØRN HOLMEDAL, Professors, are with the Department of Material Science and Engineering, Norwegian University of Science and Technology.

Manuscript submitted August 24, 2010.

Article published online July 1, 2011 empirical relationship, however, does not include any of the underlying microstructural mechanisms. Several phenomena influence the bendability, e.g., hardening behavior, constituent particles, shear band formation, microstructure, and texture/anisotropy.

Experimental findings, e.g., References 5 through 7, indicate that the presence of constituent particles influences the bendability of aluminum alloys. What part the particles play in the damage of the material, however, is still uncertain. Sarkar et al., ${ }^{[7,8]}$ in agreement with Datsko and Yang, ${ }^{[1]}$ have shown that an increasing amount of constituent iron-rich particles not only influences the bendability of an alloy, but also the tensile ductility. Ragab and Saleh ${ }^{[9]}$ and Bettaieb et al. ${ }^{[10,11]}$ took into account void growth and coalescence in modeling of bendability. Constituent particles in metals are found to be natural nucleation sites for microvoids. ${ }^{[6]}$ Dao and $\mathrm{Li}^{[12]}$ and Wilkinson et al., ${ }^{[13]}$ however, suggest that the particles also affect the formation of shear bands during bending, which essentially leads to fracture. Shear localization plays a major role in fracture initiation. ${ }^{[12,14-17]}$ In anisotropic materials such as rolled and extruded metals, the texture is found to affect the shear band formation as well. Kuroda and Tvergaard, ${ }^{[14]}$ in their finite element analyses, systematically studied the effect of different texture components with respect to strain localization.

Experiments on extruded aluminum profiles showed better bendability when the bending axis (BA) was parallel to the extrusion direction, than when it is perpendicular to it, for both recrystallized and fibrous grain morphologies. ${ }^{[18]}$ The aim of this experimental 
study is to characterize the bendability of a heattreatable AA7108 aluminum alloy and compare it to results from tensile testing, for verification of already existing numerical results. By manipulation of the microstructure, the effect of grain morphology, texture, and distribution of constituent particles on bendability and fracture mechanisms is investigated.

\section{MATERIAL AND EXPERIMENTAL PROCEDURE}

A commercial AA7108 aluminum alloy was provided by Hydro Aluminium Structures Raufoss AS in two initial conditions, namely, as extruded profiles and ascast and homogenized ingots. In addition to the two initial conditions, rolling ingots were made from the ascast and homogenized material. These were heat treated at $793 \mathrm{~K}\left(520^{\circ} \mathrm{C}\right)$ for 30 minutes, quenched, and cold rolled to a strain of 1.39 . The extruded and the as-cast and homogenized materials were solution heat treated at $753 \mathrm{~K}\left(480{ }^{\circ} \mathrm{C}\right)$ for 20 minutes, while the rolled material was solution heat treated at $793 \mathrm{~K}\left(520^{\circ} \mathrm{C}\right)$ for 20 minutes to obtain a recrystallized microstructure. To ease the reading, the three different materials will in the following be referred to as the as-cast material, the extruded material, and the recrystallized material, meaning the as-cast and homogenized material, the fibrous extruded material, and the rolled and recrystallized material, respectively. In Figure 1, the microstructures of the three materials are presented. The as-cast material has equiaxed grains with a grain size of $\sim 155$ $\mu \mathrm{m}$. The recrystallized material contains ellipsoidal grains, $\sim 14 \mu \mathrm{m}$ in the short direction normal to the rolling direction (denoted ND) and $\sim 24 \mu \mathrm{m}$ in the rolling direction. The extruded material has a fibrous microstructure with grains up to several centimeters in the extrusion direction, but only $7 \mu \mathrm{m}$ between the high-angle boundaries in the normal direction. For all the conditions, the solution heat treatment was followed by storage at room temperature for 24 hours and a two-step artificial aging, the first step being holding at $373 \mathrm{~K}\left(100{ }^{\circ} \mathrm{C}\right)$ for 5 hours followed by $423 \mathrm{~K}\left(150^{\circ} \mathrm{C}\right)$ for varying amounts of time. Based on the aging curves in Figure 2, two tempers were chosen, at 5 and 24 hours, i.e., one underaged/close to peak aged and one overaged.

For comparison of the crystallographic texture of the extruded and the recrystallized material, texture data were collected by use of standard X-ray diffraction in a Siemens D5000 diffractometer (Bruker-AXS, Delft, Netherlands) for the two conditions. Orientation distribution functions (ODFs) were calculated assuming orthotropic sample geometry. A random crystallographic texture was assumed for the as-cast material, in accordance with general experience. Due to the large
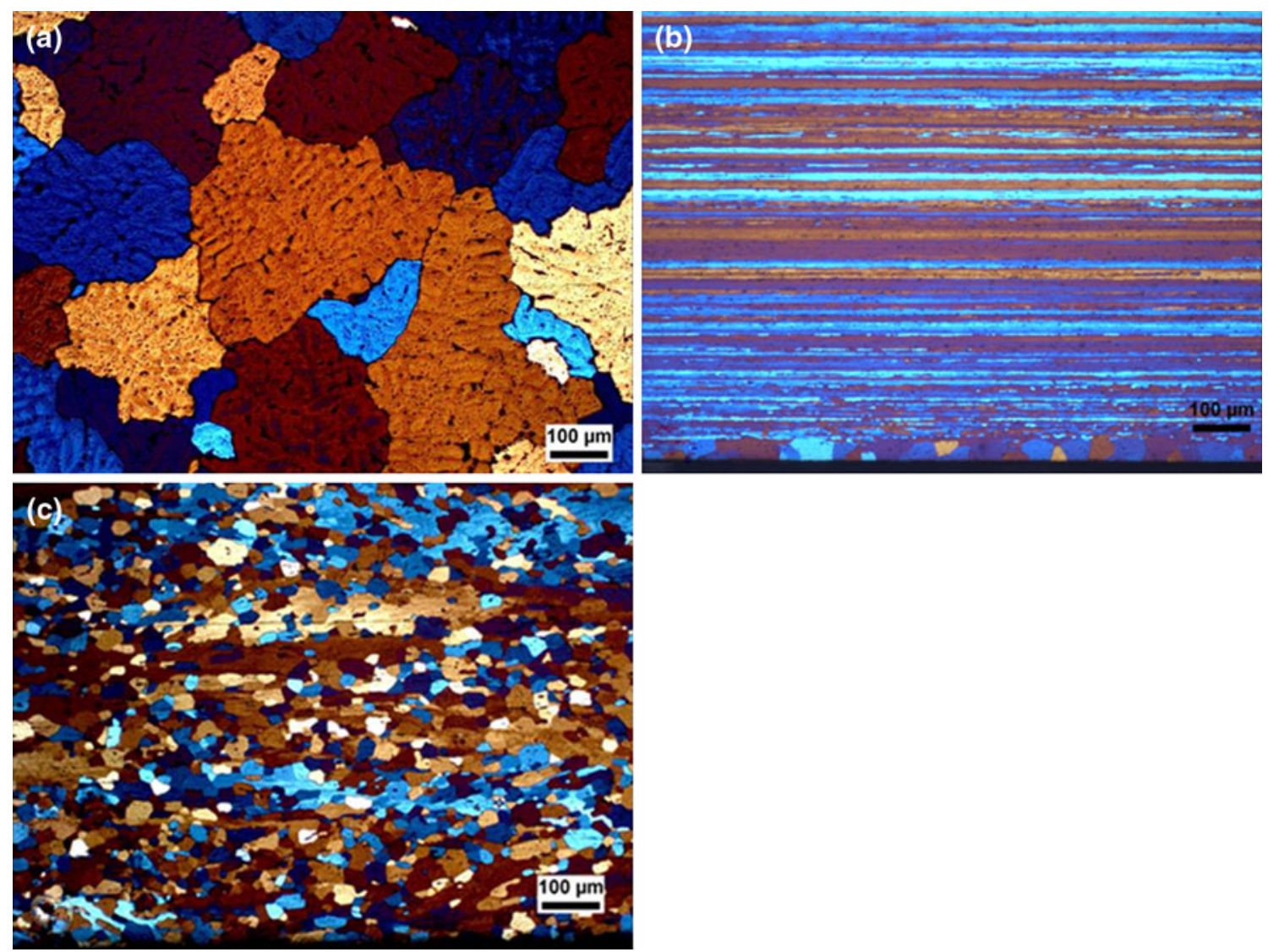

Fig. 1-Microstructure of the AA7108 base material: (a) as-cast and homogenized material, $(b)$ fibrous as-extruded material with a recrystallized surface layer, and $(c)$ rolled and recrystallized material. 


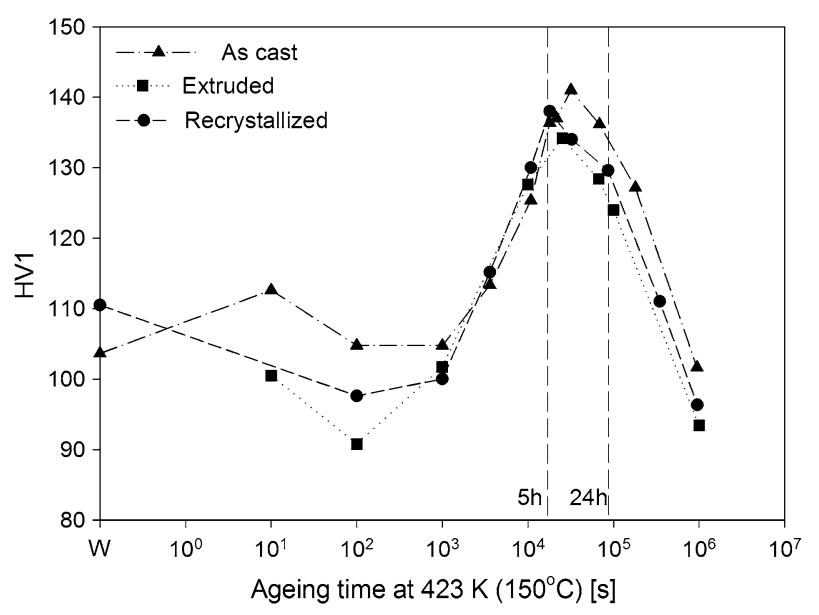

Fig. 2-Aging curves for all three materials.

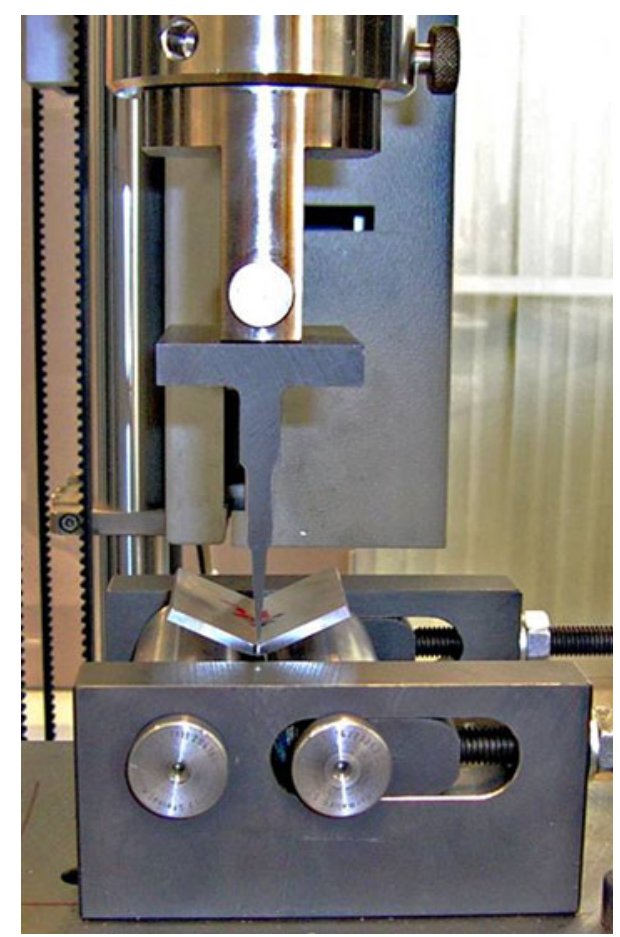

Fig. 3-Zwick test machine equipped with tools for three-point plane-strain bending.

grain size, the numbers of grains in a specimen are insufficient for a statistically reliable texture analysis and, therefore, is not performed.

To further characterize the anisotropy of the extruded and recrystallized materials, respectively, standard tensile specimens were made in 0,45 , and $90 \mathrm{deg}$ with respect to the deformation direction (extrusion direction or rolling direction). Before testing, the tensile specimens were heat treated to the 5- and 24-hour tempers. Tensile testing was carried out at a constant nominal strain rate of $0.01 \mathrm{~s}^{-1}$ for the extruded material and $0.003 \mathrm{~s}^{-1}$ for the recrystallized material in an MTS810 hydraulic test machine. As a reference, the as-cast material was tensile tested in the 5-hour condition with a nominal strain rate

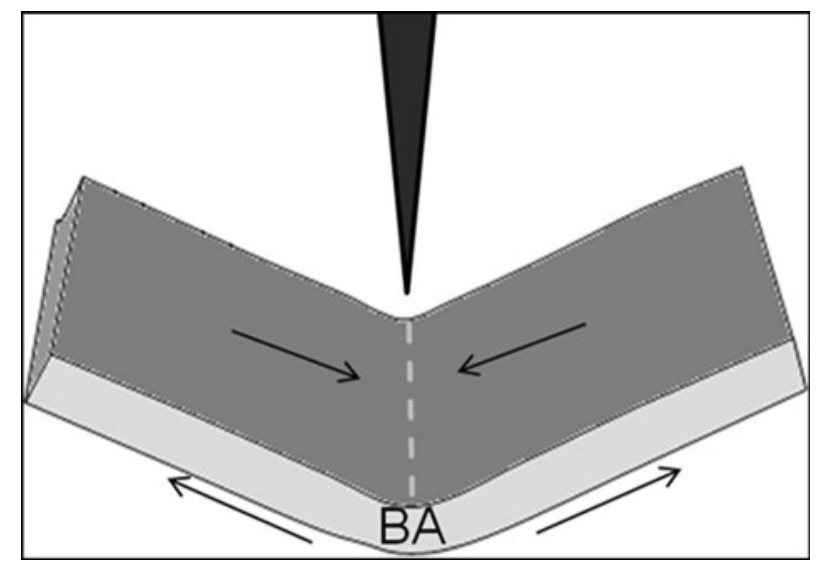

Fig. 4-Schematic illustration of the major stresses present in threepoint bending and their directions relative to the BA.

of $0.01 \mathrm{~s}^{-1}$. The reduction in area after fracture was measured by use of image processing on the crosssectional projection of the fracture surface.

Specimens for three-point bending were machined from all three materials. The dimensions were $60 \mathrm{~mm} \times$ $60 \mathrm{~mm} \times 3.17 \pm 0.04 \mathrm{~mm}$ for the extruded material and $50 \mathrm{~mm} \times 50 \mathrm{~mm} \times 2.96 \pm 0.09 \mathrm{~mm}$ for the recrystallized and as-cast materials. The bending specimens were then heat treated to the 5- and 24-hour temper. Threepoint plane-strain bending tests were performed with the BA along either the deformation direction (ED is used throughout the rest of the article) or the transverse direction (TD) for both the extruded and the recrystallized samples. In addition the extruded material was tested in the $45 \mathrm{deg}$ direction. Due to geometrical restrictions, this was not possible with the recrystallized material. For the as-cast material, the BA was chosen arbitrarily, independent of direction. The tests were performed in a Zwick testing machine (Figure 3) according to guidelines proposed by Daimler Chrysler. ${ }^{[19]}$ A constant vertical speed of $20 \mathrm{~mm} / \mathrm{min}$ was chosen, and the roll gap was 2 times the specimen thickness plus $0.2 \mathrm{~mm}$. Force was logged as a function of vertical displacement, and the test was stopped when the force-displacement curve showed a significant drop. Figure 4 illustrates the bending stresses and their direction relative to the $\mathrm{BA}$ in a three-point bending test. The figure schematically shows how the test specimen experiences tension on the lower surface and compression on the upper surface (against the knife). These stresses act perpendicular to the BA. This means that when comparing anisotropy in bending and in tension, the BA should be perpendicular to the direction of the tensile specimen to obtain tension in the same direction. However, it should be noted that the stress states in bending and uniaxial tension are different. In bending, there are also stresses parallel to the BA. These are compressive on the upper surface and tensile on the lower surface ( $c f$. Figure 4).

The bending angle was measured manually afterwards according to standard procedures, ${ }^{[19]}$ and the bending radius was determined by use of macrographs and image processing. A cut was made perpendicular to the BA, 
allowing the microstructure and the fracture propagation to be examined by light optical microscopy.

After three-point bending, the deformed samples of the as-cast and the recrystallized materials were further bent until failure and the fracture surfaces were investigated in a Zeiss Gemini Supra 55 VP FESEM (Carl Zeiss International, Germany). To investigate whether the presence of constituent particles influences the bendability, the distribution of primary particles was also investigated in the ED-ND plane and the TD-ND plane of the recrystallized material in SEM.

\section{RESULTS}

The macrotextures of the extruded and the recrystallized materials are presented in Figure 5 in the form of ODFs. The extruded material in Figure 5(a) shows a typical deformation texture with a strong $\beta$ fiber running from the Bs orientation over the $\mathrm{S}$ orientation to the $\mathrm{Cu}$ orientation. Intensities of the cube orientation are also observed in the 0 deg section. The macrotexture of the recrystallized material in Figure 5(b) reveals a very weak retained deformation texture from cold rolling (note

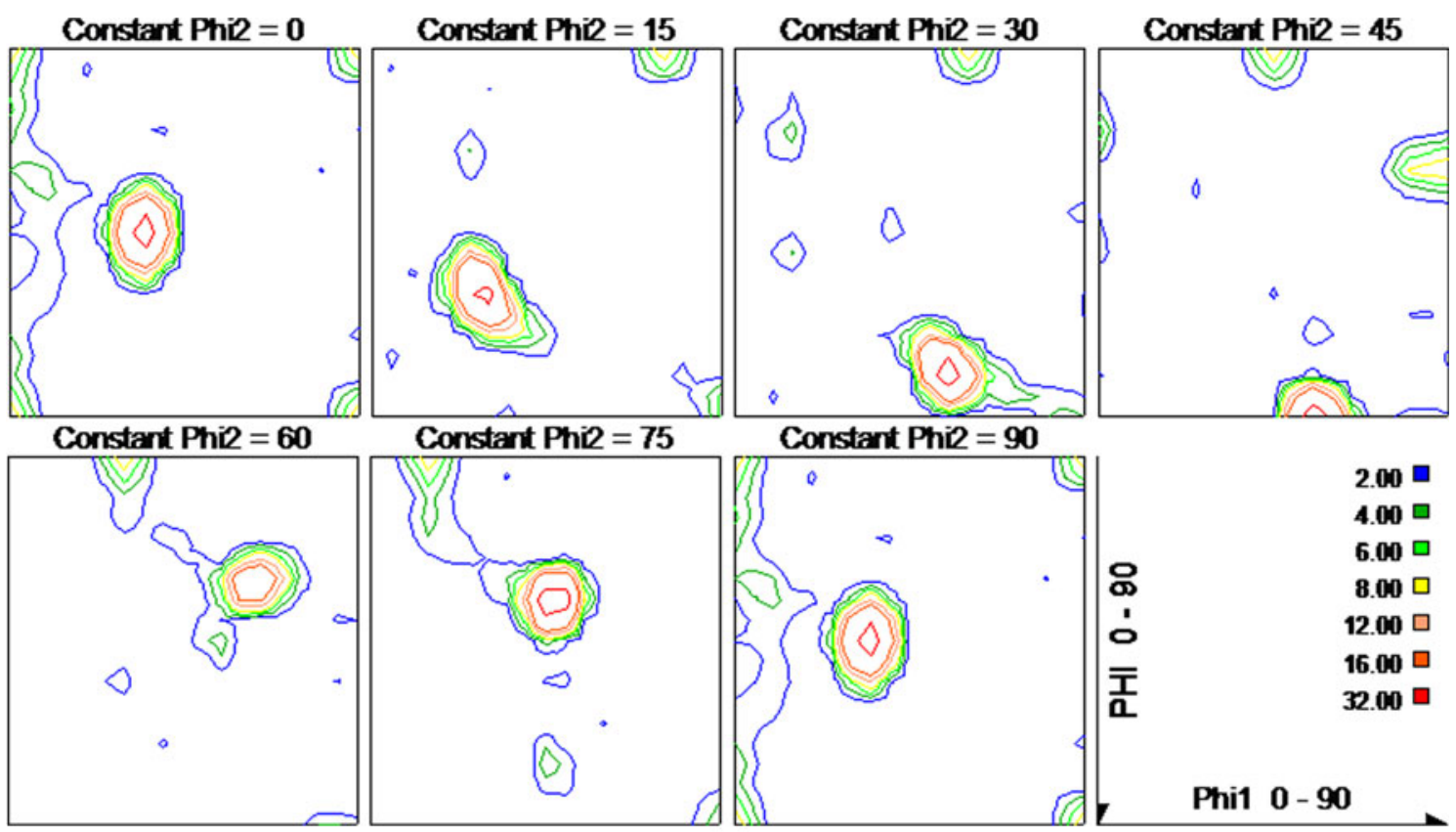

(a)
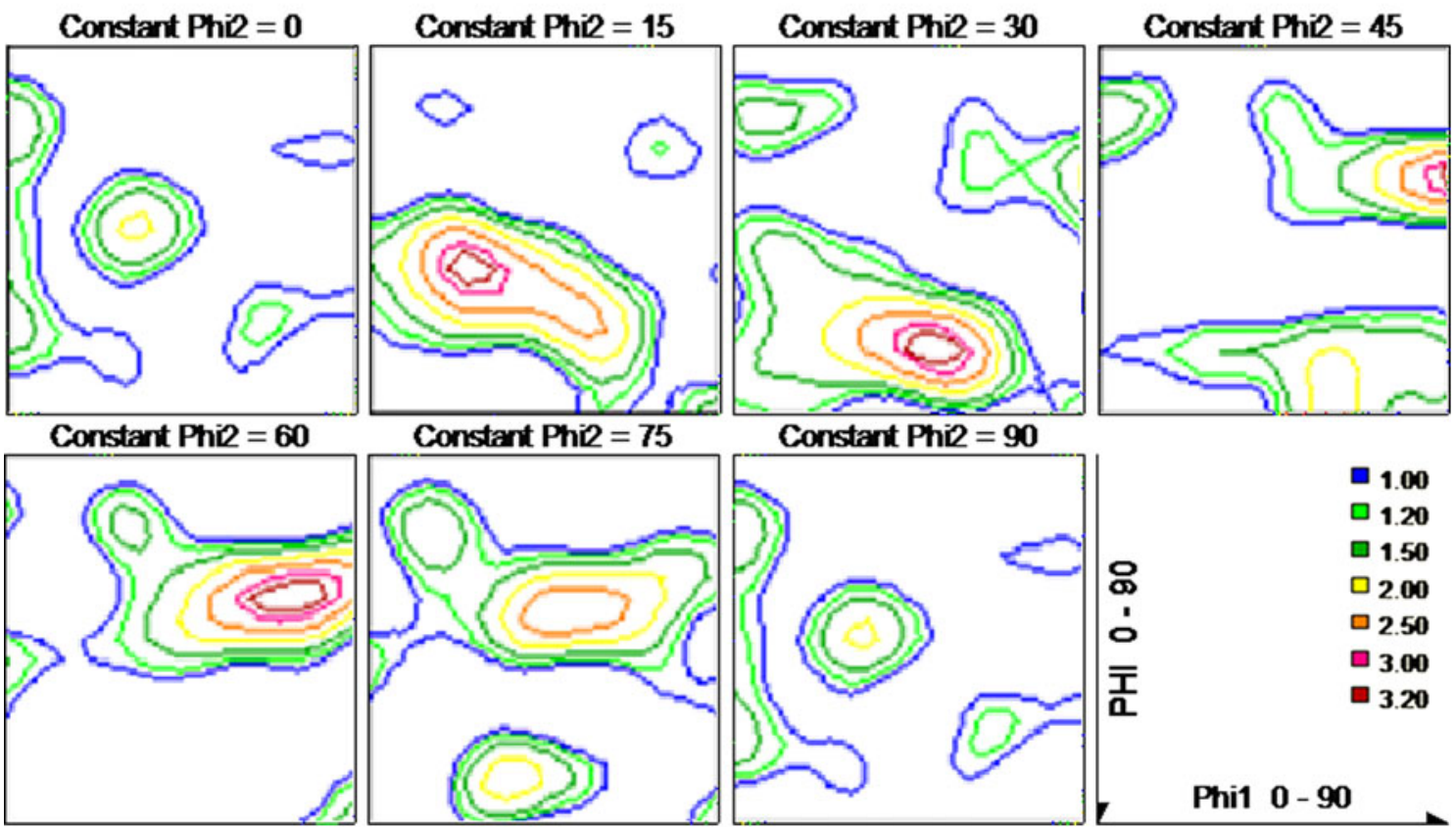

(b)

Fig. 5-ODFs obtained for $(a)$ the extruded material and $(b)$ the rolled and recrystallized material. 
that there is a factor 10 in difference between the maximum levels in the two ODFs, with a maximum of only 3.2 in the latter).

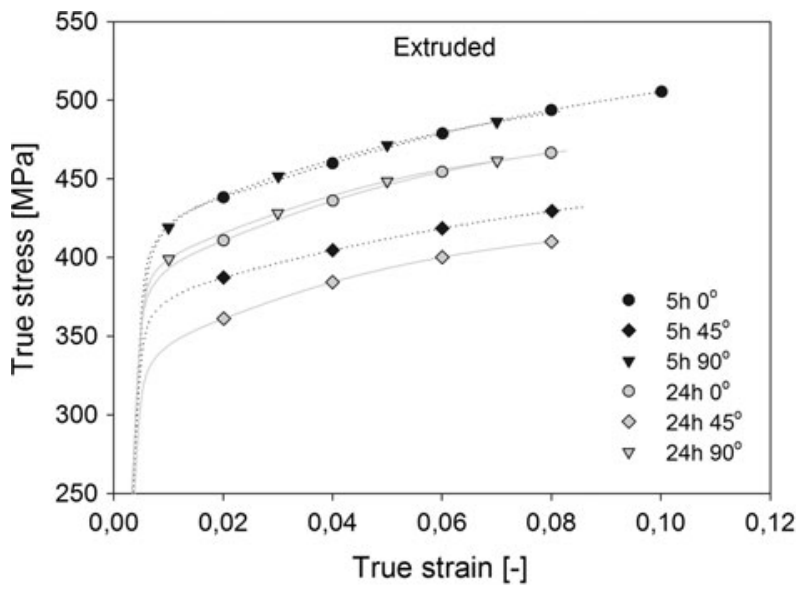

(a)

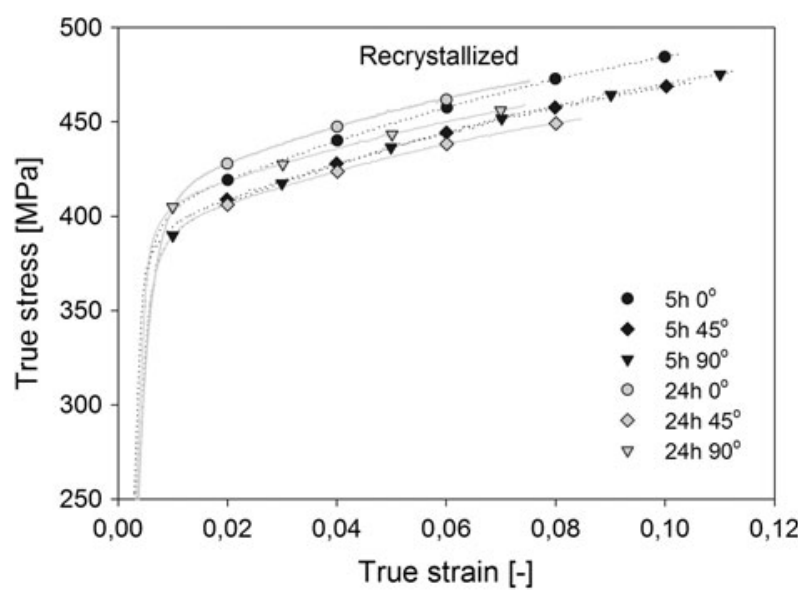

(b)

Fig. 6-True stress-strain curves to ultimate tensile strength in the directions 0,45 , and $90 \mathrm{deg}$ with respect to the deformation direction for the two tempers of $(a)$ the extruded material and $(b)$ the recrystallized material.
The true stress-strain curves for the extruded and recrystallized materials are presented in Figure 6. Regarding the extruded material in Figure 6(a), the strength and uniform elongation of the underaged samples, in general, are higher than for the overaged ones in the respective directions. The strength is at the same level with the tensile direction aligned 0 and 90 deg to the extrusion direction, whereas the strength in the $45 \mathrm{deg}$ direction is significantly lower. The uniform elongation, however, is lower in the $90 \mathrm{deg}$ direction. This holds for both tempers. From Figure 6(b), less differences are observed for the recrystallized material, both with respect to tempers and to tensile directions. Also, for the recrystallized material, the uniform elongation is lower for the overaged temper. For comparison, the true stress-strain curves are plotted for all three materials of the 5-hour temper in Figure 7. Only the directions with the extreme behaviors were included for the two deformed conditions, i.e., the 0 and $45 \mathrm{deg}$ directions. The extruded material represents the two extremes with the $45 \mathrm{deg}$ as the weakest and the $0 \mathrm{deg}$ as the strongest direction. The as-cast and the recrystallized materials lie in between. The recrystallized material is

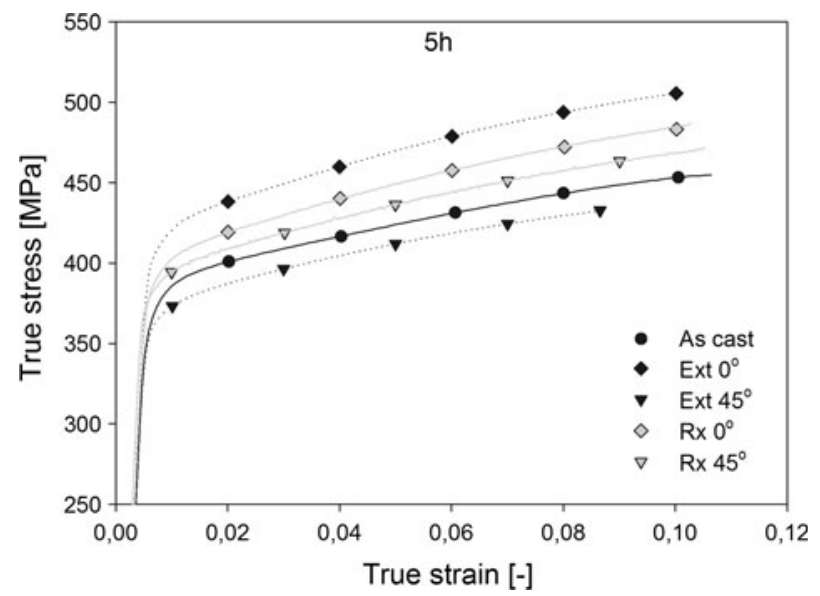

Fig. 7-True stress-strain curves for all three materials in the underaged $5 \mathrm{~h}$ temper.

Table I. 0.2 Pct Offset Yield Strength, Ultimate Tensile Strength, Uniform Strain, and Reduction in Area after Fracture for the Extruded and Recrystallized Material

\begin{tabular}{|c|c|c|c|c|c|c|}
\hline Material & Temper & $\begin{array}{l}\text { Deformation Direction } \\
\text { in Degrees Compared to the ED }\end{array}$ & $R_{p 0.2}(\mathrm{MPa})$ & $R_{m}(\mathrm{MPa})$ & $e_{u}(\mathrm{~mm} / \mathrm{mm})$ & $q(\mathrm{Pct})$ \\
\hline As-cast & $5 \mathrm{~h}$ & - & 371 & 409 & 0.099 & 10.1 \\
\hline \multirow[t]{3}{*}{ Extruded } & $5 \mathrm{~h}$ & 0 & 406 & 506 & 0.103 & 12.8 \\
\hline & & 45 & 363 & 431 & 0.085 & 42.3 \\
\hline & & 90 & 408 & 494 & 0.084 & 19.5 \\
\hline \multirow[t]{3}{*}{ Extruded } & $24 \mathrm{~h}$ & 0 & 378 & 466 & 0.082 & 18.9 \\
\hline & & 45 & 333 & 410 & 0.077 & 45.3 \\
\hline & & 90 & 390 & 462 & 0.071 & 23.4 \\
\hline \multirow[t]{3}{*}{ Recrystallized } & $5 \mathrm{~h}$ & 0 & 383 & 437 & 0.107 & 21.2 \\
\hline & & 45 & 378 & 426 & 0.101 & 28.7 \\
\hline & & 90 & 376 & 427 & 0.104 & 16.1 \\
\hline \multirow[t]{3}{*}{ Recrystallized } & $24 \mathrm{~h}$ & 0 & 380 & 438 & 0.078 & 22.2 \\
\hline & & 45 & 372 & 416 & 0.084 & 31.9 \\
\hline & & 90 & 392 & 429 & 0.084 & 23.8 \\
\hline
\end{tabular}




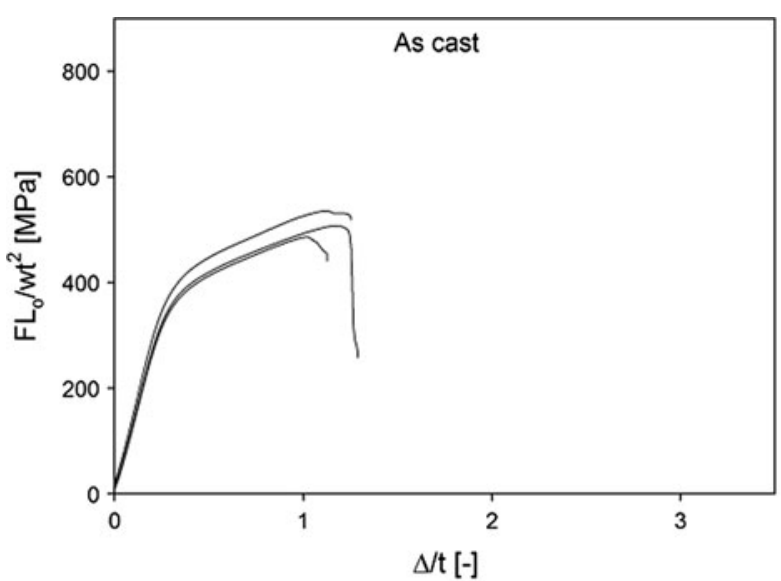

(a)

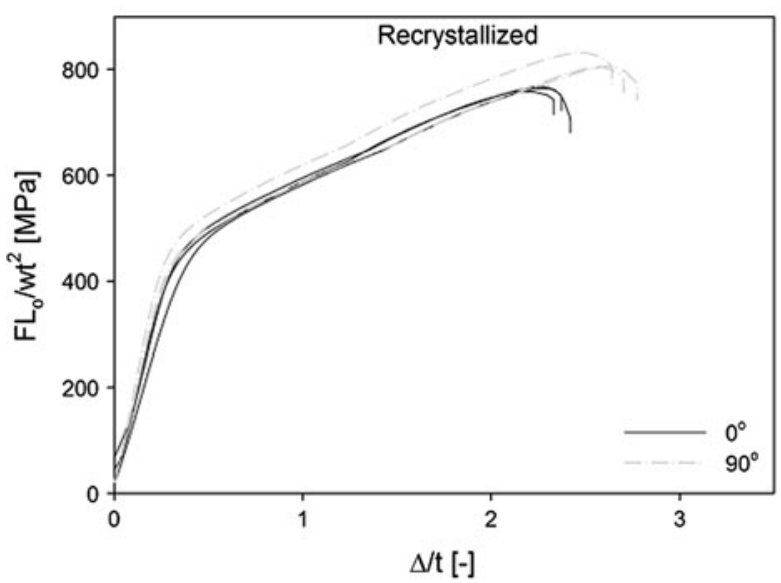

(c)

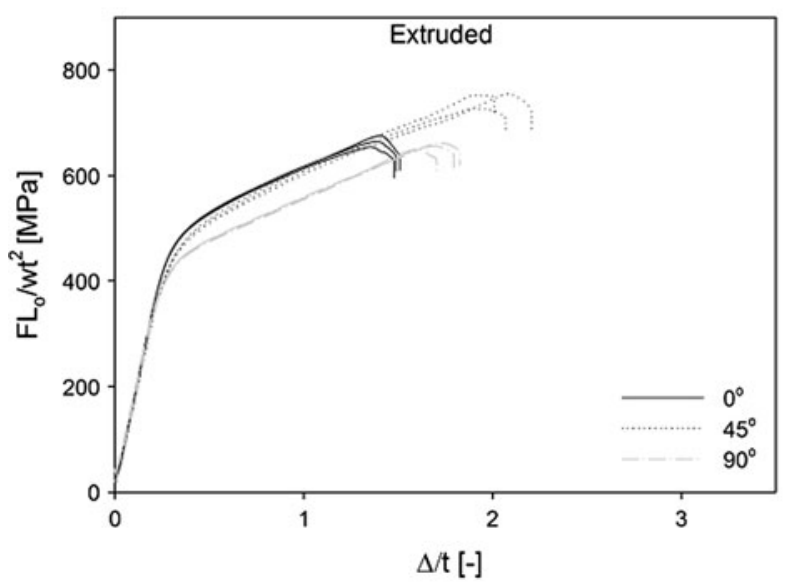

(e)

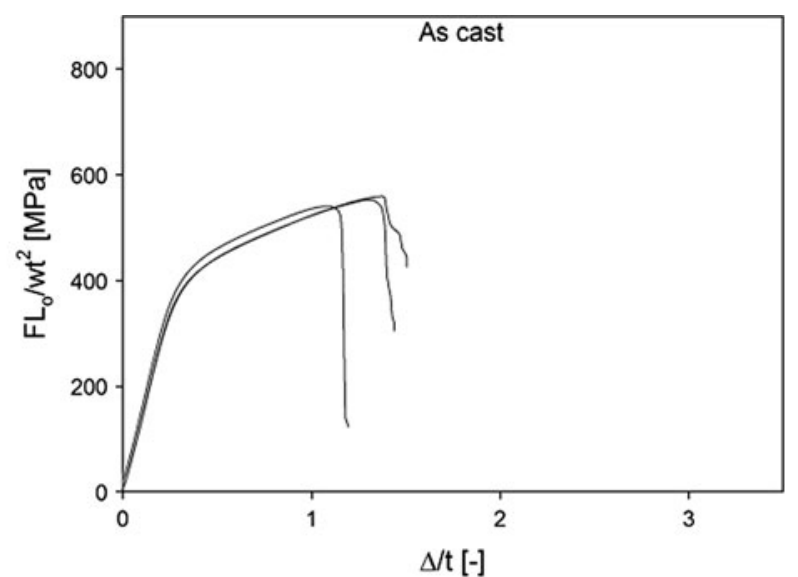

(b)

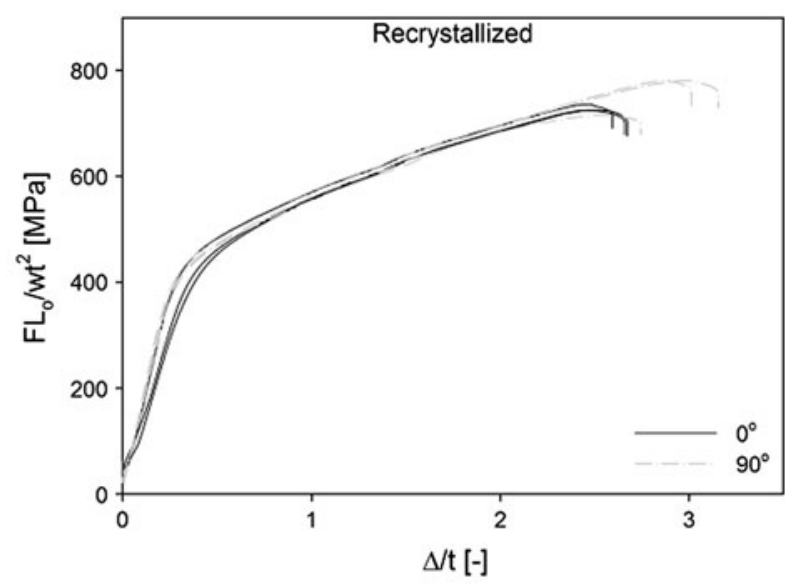

(d)

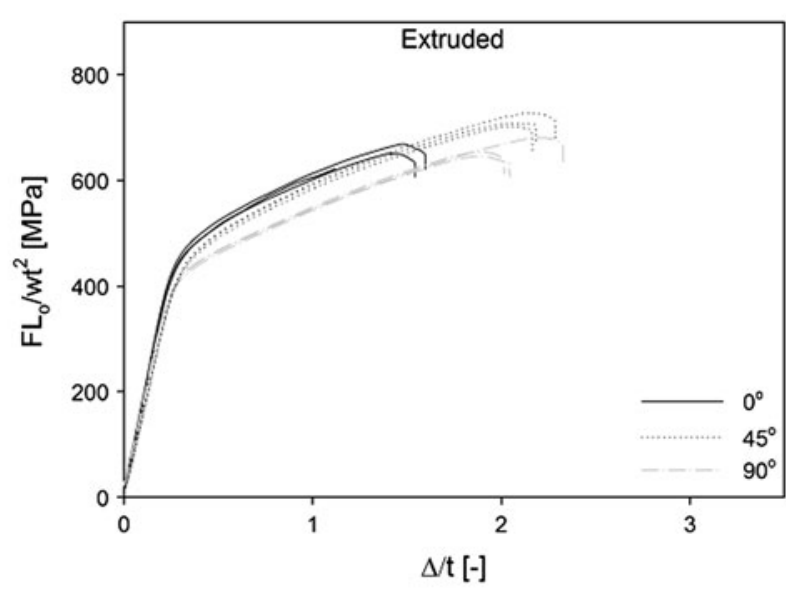

(f)

Fig. 8- The normalized force-displacement curves from the three-point bending test: $(a),(c)$, and $(e)$ the material aged for $5 \mathrm{~h}$ at $423 \mathrm{~K}\left(150{ }^{\circ} \mathrm{C}\right)$ in the as-cast, recrystallized, and extruded conditions, respectively; and $(b),(d)$, and $(f)$ the material aged for $24 \mathrm{~h}$ at $423 \mathrm{~K}\left(150{ }^{\circ} \mathrm{C}\right)$ in the same conditions.

somewhat stronger than the as-cast one. All materials show similar work-hardening behaviors. In Table I, the 0.2 pct offset yield strength $\left(R_{p 0.2}\right)$, ultimate tensile strength $\left(R_{m}\right)$, uniform strain $\left(\varepsilon_{u}\right)$, and reduction in area after fraction $(q)$ are listed for the three directions of the extruded and recrystallized material, as well as for the ascast 5-hour temper. The values for yield and ultimate tensile strength reflect the observations in the true stressstrain curves. The reduction in area is used as a measure for the ductility in tension. The extruded material experiences 
Table II. Measured Bending Angles after Three-Point Bending and Typical Values of the Bendability for All Three Materials

\begin{tabular}{|c|c|c|c|c|c|c|}
\hline \multirow[b]{2}{*}{ Condition } & \multirow[b]{2}{*}{ Temper } & \multirow[b]{2}{*}{ BA } & \multirow{2}{*}{$\begin{array}{l}\text { Deformation Direction } \\
\text { in Degrees Compared } \\
\text { to the ED }\end{array}$} & \multicolumn{2}{|c|}{ Measured Bending Angle } & \multirow{2}{*}{$\begin{array}{c}\text { Bendability } \\
r / t(-)\end{array}$} \\
\hline & & & & $\begin{array}{l}\text { Average } \\
\text { (Deg) }\end{array}$ & $\begin{array}{c}\text { Standard } \\
\text { Deviation (Deg) }\end{array}$ & \\
\hline \multirow[t]{2}{*}{ As-cast } & $5 \mathrm{~h}$ & - & - & 22 & 2.5 & 3.00 \\
\hline & $24 \mathrm{~h}$ & - & - & 26 & 2.3 & 2.83 \\
\hline \multirow[t]{6}{*}{ Extruded } & $5 \mathrm{~h}$ & TD & 0 & 37 & 1.7 & 1.38 \\
\hline & & 45 & 45 & 45 & 3.1 & 0.94 \\
\hline & & ED & 90 & 28 & 0.6 & 1.78 \\
\hline & $24 \mathrm{~h}$ & TD & 0 & 46 & 4.9 & 0.94 \\
\hline & & 45 & 45 & 47 & 1.7 & 1.00 \\
\hline & & ED & 90 & 32 & 1.2 & 1.43 \\
\hline \multirow[t]{4}{*}{ Recrystallized } & $5 \mathrm{~h}$ & TD & 0 & 61 & 2.1 & 0.62 \\
\hline & & ED & 90 & 49 & 1.0 & 1.03 \\
\hline & $24 \mathrm{~h}$ & TD & 0 & 66 & 7.0 & 0.70 \\
\hline & & ED & 90 & 56 & 0.6 & 0.74 \\
\hline
\end{tabular}
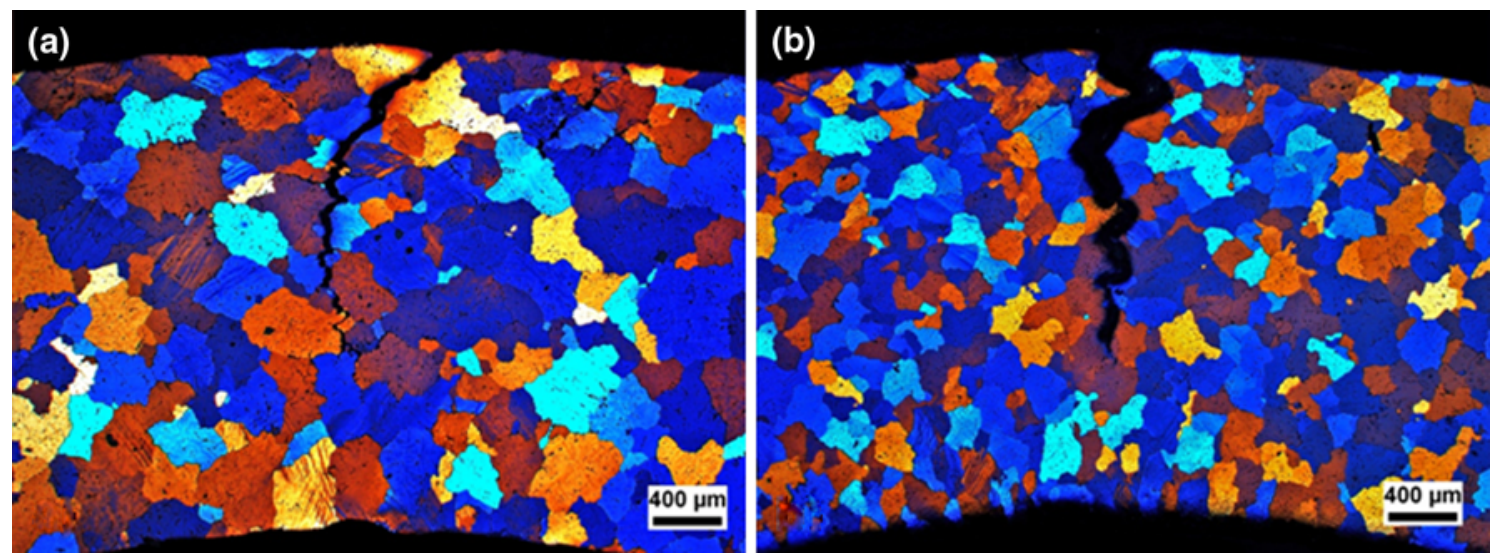

Fig. 9-Micrographs of the deformed as-cast material: (a) the $5 \mathrm{~h}$ temper and (b) the $24 \mathrm{~h}$ temper.

large differences dependent on direction. In the $45 \mathrm{deg}$ direction, the reduction in area is more than twice that observed in 0 and $90 \mathrm{deg}$. The ductility is slightly higher for the overaged 24-hour temper for both the extruded and the recrystallized materials. For the recrystallized material, the reduction in area is more consistent for the three directions, but still a little higher in $45 \mathrm{deg}$.

Based on the force-displacement curves from the three-point bending tests, the force $(F)$ was normalized with the widths $(w)$, thicknesses $(t)$ of the specimens, and the distance between the rollers $\left(L_{0}\right)$. The normalized force is shown $v s$ the normalized vertical displacement $(\Delta / t)$ in Figure 8 for the different materials. Figures 8(a), (c), and (e) show the 5-hour temper and (b), (d), and (f) the 24-hour temper. Both tempers show the same trend with respect to the different materials. The as-cast material is lowest in normalized force and, in particular, low in vertical displacement. Both directions of the recrystallized material experience the same magnitude of normalized force. However, when the BA is aligned $90 \mathrm{deg}$ with respect to the rolling direction, a much higher vertical displacement is achieved. The extruded material, on the other hand, shows a difference in both normalized force and displacement, depending on the direction of the BA. When the $\mathrm{BA}$ is along the extrusion direction ( $0 \mathrm{deg}$ ), the normalized force is higher, but the displacement is lower compared to the samples with the $\mathrm{BA}$ oriented along the TD. The normalized force is at the same level for the samples aligned $45 \mathrm{deg}$ to the extrusion direction compared to those aligned along the extrusion direction. The obtainable displacement, however, is higher in 45 deg than in the other two directions.

The test was stopped as soon as a significant drop in force was observed, as reflected by the curves. Subsequent to unloading, the bending angles were measured for all the materials and are listed in Table II along with a typical value of the $r / t$ ratio. The as-cast material is independent of direction and shows the poorest bendability for both tempers compared to the other materials. Best performance is observed for the recrystallized material, while the bending angle of the extruded material is somewhat lower. When comparing the difference between the two tempers, the overaged 24-hour temper has a higher bending angle than the 5-hour temper for the respective directions of all the materials. For the extruded material, the best results are achieved with the BA aligned $45 \mathrm{deg}$ to the extrusion direction. Comparing the results only with the BA 

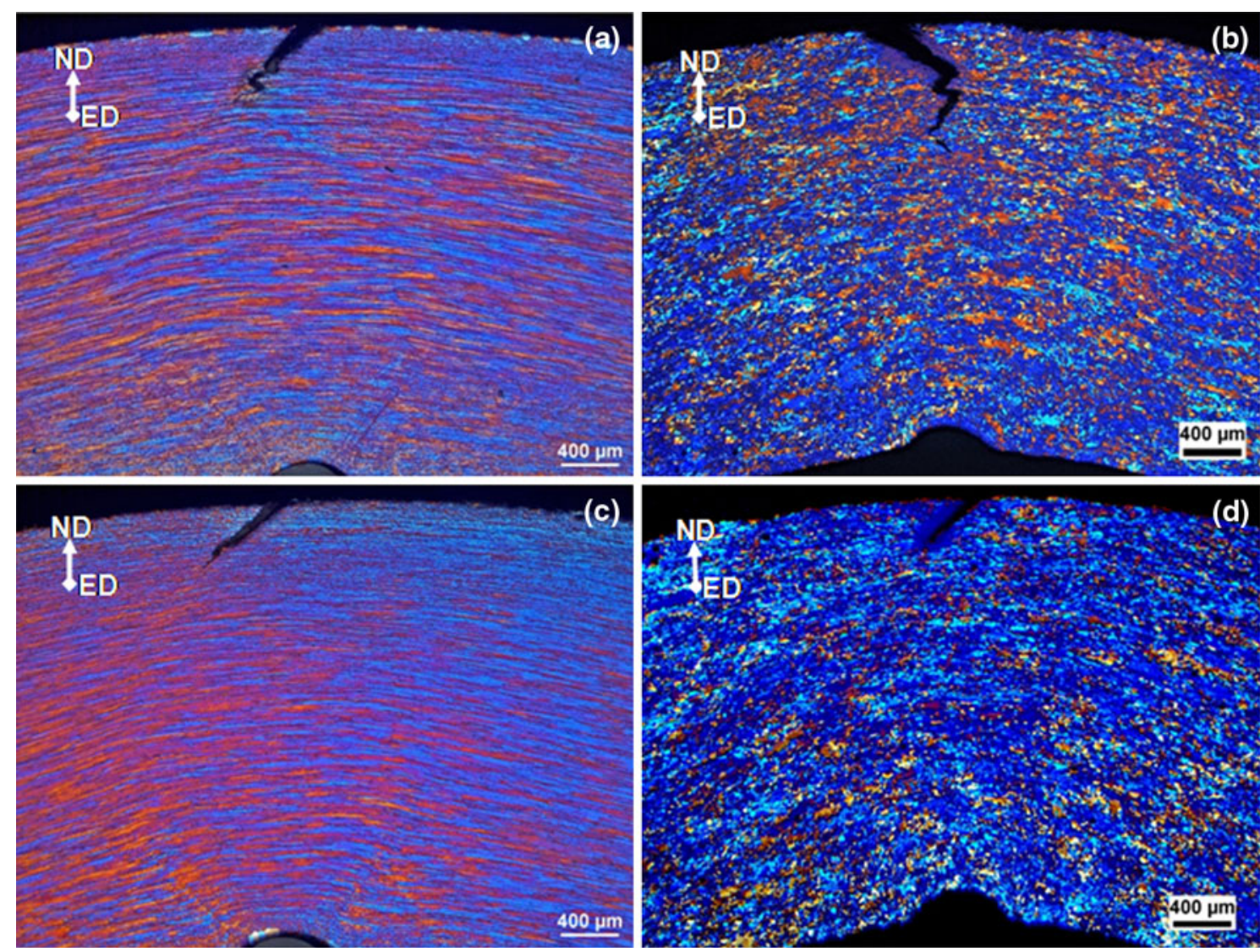

Fig. 10-Micrographs of the $(a)$ and $(c)$ extruded and $(b)$ and $(d)$ recrystallized materials deformed with the BA along the ED. The underaged $5 \mathrm{~h}$ tempers are in (a) and (b), and the overaged $24 \mathrm{~h}$ tempers are in (c) and (d).

aligned along the extrusion direction or the TD (excluding the $45 \mathrm{deg}$ direction), the highest angles and best bendability are obtained with the BA in the TD. This applies to both tempers of the extruded and the recrystallized materials.

The crack propagation in the materials deformed by three-point bending was investigated by use of lightoptical microscopy. A through-thickness overview of the crack propagation in the two as-cast tempers is presented in Figure 9. Both the 5-hour temper in (a) and the 24-hour temper in (b) show a combination of intercrystalline and transcrystalline fracture modes.

In the case where the materials were predeformed and heat treated before aging, i.e., the extruded and the cold rolled and recrystallized materials, three-point bending was carried out with the BA along both the ED and TD. Figure 10 shows an overview of the samples deformed with the BA along ED. Figures 10(a) and (b) show the 5-hour tempers of the extruded and recrystallized material, respectively. The 24-hour tempers of the extruded and recrystallized materials, in turn, are illustrated in (c) and (d). In all the cases, the fracture is initiated as a shear fracture on the tension side of the samples, and as the crack propagates, the mode turns into a mixture of intercrystalline and transcrystalline crack growth, which is most pronounced for the 5-hour temper. On the compression side of both the extruded tempers in (a) and (c), intense shear band formation is observed symmetrically on both sides of the BA. This phenomenon is not observed for the recrystallized samples. In the case where the BA is aligned along the TD (Figure 11), the crack propagates from the tension side of the sample as a transcrystalline shear fracture. This holds independent of microstructure and temper. While the crack front is intense and narrow for the 5-hour temper of the extruded material in (a), the 24-hour temper has a somewhat broader crack tip (Figure 11(c)).

The deformed samples of the as-cast and recrystallized materials were further bent until failure, and the fracture surfaces were investigated in SEM. The SEM images of the as-cast material are shown in Figures 12(b) and (d) along with the corresponding optical micrographs in (a) and (c) for the 5- and 24-hour tempers, respectively. The optical micrograph of the 5-hour temper in (a) shows a narrow and very "clean" crack compared to the broader crack in the 24-hour temper in (c) (also Figure 9). The transcrystalline parts of the crack seem to occur where there is a high density of constituent particles. In the 5-hour sample, small intercrystalline secondary cracks perpendicular to the crack front are observed in the micrograph. These are clearly distinguished in the SEM image in Figure 12(b). The fracture surface of the 24-hour temper in Figure 12(d) shows more dimples than the 5 hour temper. Pores on the ridge indicated by arrows in (d) are caused by alignment of primary particles in the cast structure. 

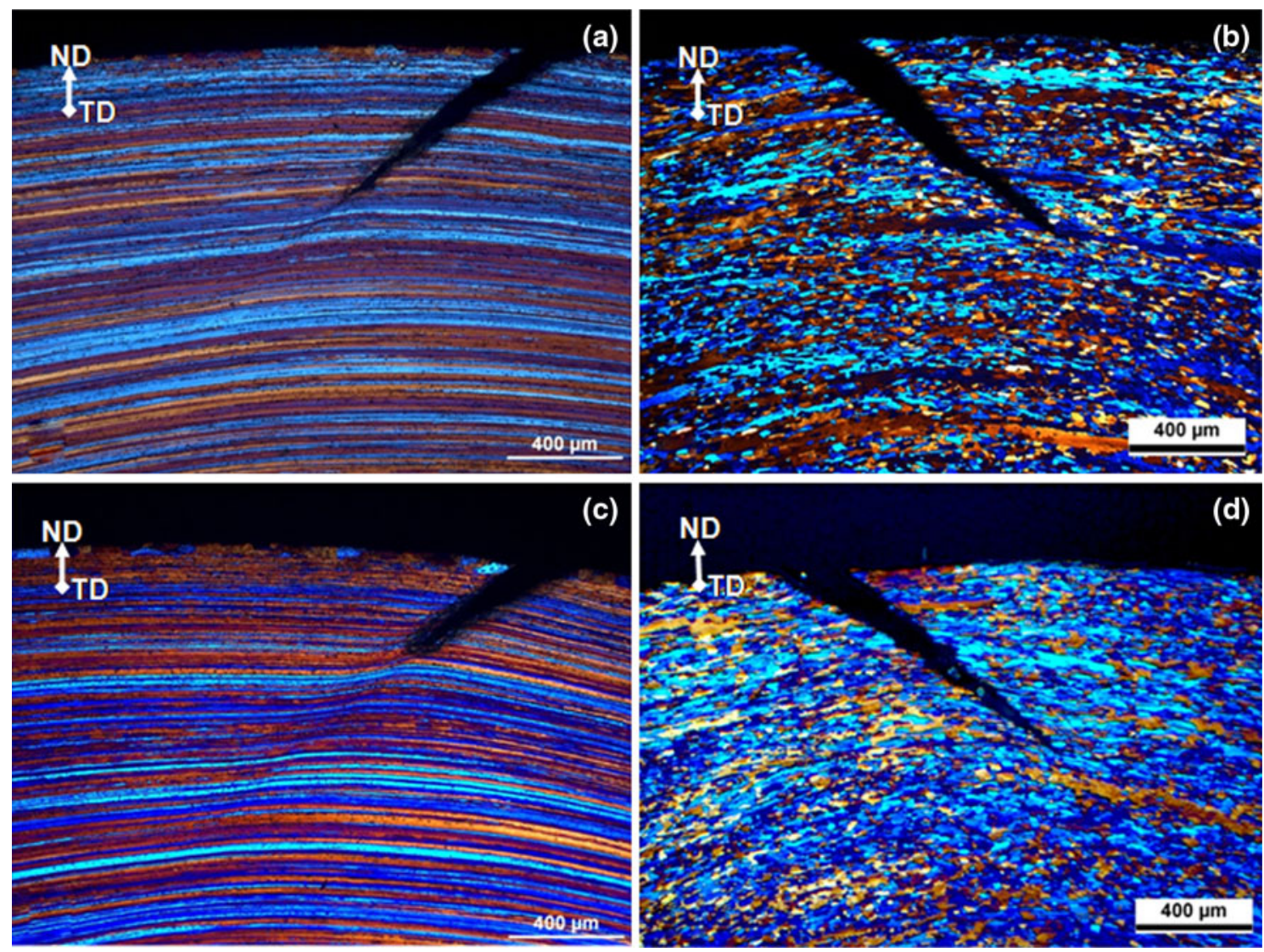

Fig. 11-Micrographs of the $(a)$ and $(c)$ extruded and $(b)$ and $(d)$ recrystallized materials deformed with the BA along the TD. The underaged $5 \mathrm{~h}$ tempers are in (a) and (b), and the overaged $24 \mathrm{~h}$ tempers are in (c) and (d).

In Figure 13, two fracture types are shown for the recrystallized 5-hour temper. In (a) and (b), the BA was aligned along the ED. The fracture shows a characteristic zigzag shape, and the fracture surface reveals stringers of primary particles along the extrusion direction (indicated by small arrows) in (b). In (c) and (d), the BA was aligned along the TD, which gives a $45 \mathrm{deg}$ shear fracture (Figure 13(c)). The fracture surface in (d), at the edge of the sample, shows transcrystalline cleavage. Note that there is a difference in magnification between (b) and (d).

The particle distribution in the ED-ND and TD-ND planes for the recrystallized material is illustrated in Figures 14(a) and (b), respectively. The rolling process before recrystallization caused the primary particles to line up like beads on a string along the rolling direction (ED), as pointed out by arrows in Figure 14(a). In the TD-ND plane in Figure 14(b), however, the particles are more randomly distributed.

\section{DISCUSSION}

From the tensile data, it is interesting to find that the strength of all three materials lies within the window defined by the two extremes of the extruded material for the given tempers, i.e., a deviation less than 15 pct from the maximum strength. The uniform strain varies little between the three materials (cf. Table I), though it is a little lower for the overaged conditions. For the extruded material, there is a slight decrease in uniform strain from the 0 to the $90 \mathrm{deg}$ direction. This is, however, not a consistent observation for the recrystallized tempers. There is, in other words, no clear correlation between uniform strain and bendability. Regarding $q$ (reduction in cross-sectional area after fracture), there is a much larger difference between the materials. However, the trend in most of the cases contradicts the bendability, except for the recrystallized underaged material in the $90 \mathrm{deg}$ direction. The observed anisotropic behavior in bending, therefore, must be explained by other influencing factors. Figure 15 illustrates the bendability $(r / t)$, plotted as a function of the reduction in area, $q$. The given direction here refers to the tensile direction. The full lines are relationships suggested by Datsko and Yang. ${ }^{[1]}$ In most cases, the bendability observed in this work is better than the predictions by Datsko and Yang (the lower the $r / t$ ratio, the better the bendability). Except for the ascast material, there is no large scattering in the $r / t$ ratios. The extruded material, however, does show a much larger spread in the $q$ value depending on the tensile direction.

The as-cast material shows the poorest behavior in three-point bending. The investigations of the crack propagation (Figure 9) reveal a different pattern 

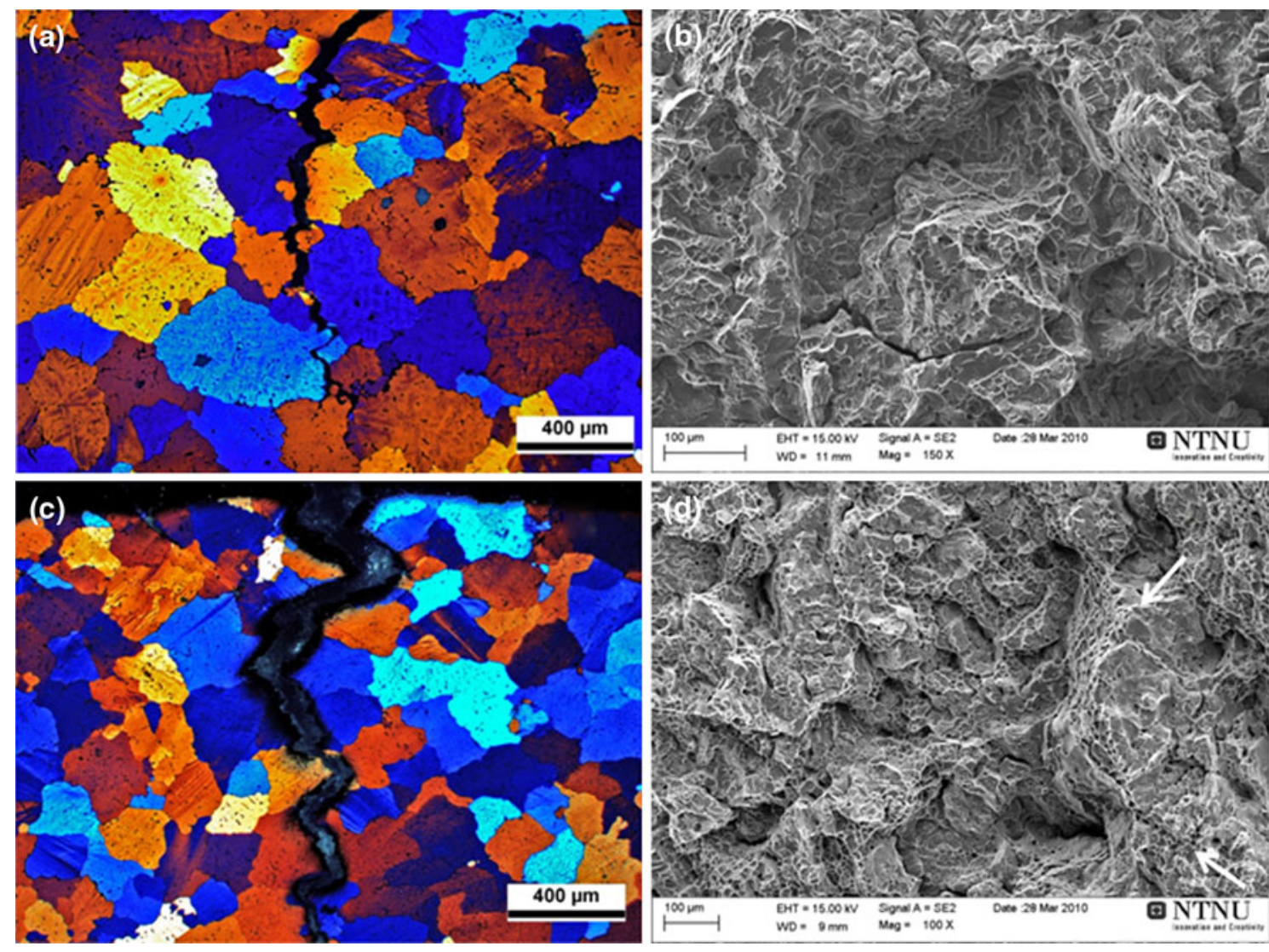

Fig. 12 - (a) through $(d)$ Optical micrographs and SEM images of the fracture surface of the as-cast material. The $5 \mathrm{~h}$ temper is in (a) and (b), and the $24 \mathrm{~h}$ temper is in (c) and (d). The arrows in (d) indicate a ridge with a high density of pores caused by particles.

compared to the two other materials. In the as-cast material, the crack follows a path along the highest density of primary particles, i.e., along grain boundaries and in the dendritic as-cast structure in the grain interior. Compared to the recrystallized material, the grain size in the as-cast material is more than 10 times larger, and it is hard to obtain compatibility between the grains during three-point bending. The reason for the poor bendability seen for the as-cast material, therefore, is most likely due to the large grains and the primary particles in the as-cast and homogenized structure.

In general, the overaged 24-hour temper reveals better bendability for all three materials. In the 24-hour temper of the as-cast and the extruded materials, a broader plastic zone is observed around the crack front (Figures 9(b) and 11(c)). Hence, the plastic zone covers a much larger area, leading to a larger dissipation of energy and, thus, a better bendability. However, this is not seen to the same extent in the recrystallized material in Figure 11(d). Dumont et al. ${ }^{[20,21]}$ discussed the factors that influence the fracture resistance, i.e., yield stress inhomogeneity, strain hardening, and grain boundary precipitation. Here, yield stress inhomogeneity means the differences in yield stress between the grain interior and precipitate-free zones along the grain boundary. Their investigations covered the notch resistance of two $7 \mathrm{xxx}$ alloys subjected to Kahn tear testing. Even though the specimen in a three-point bending test experiences a less complex deformation mode, the same deductions regarding fracture resistance should be applicable in this case. The recrystallized and the extruded overaged materials are similar in yield stress and strain hardening ( $c f$. Figure 6 and Table I). No large difference in grain boundary precipitation is expected between the underaged and overaged tempers. The reason for the large plastic zone in the overaged 24-hour materials, therefore, should be found in the interaction between dislocations and the nonshearable precipitates in a soft depleted matrix. However, further investigations are necessary to gain more knowledge about this interaction.

Strain localization in the form of shear band formation is the major failure initiation mechanism in three-point bending of the predeformed materials. In plane-strain bending, the material is already in a favorable stress state for shear band formation compared to uniaxial tension. Both $\mathrm{Dao}$ and $\mathrm{Li}^{[12]}$ and Sarkar et al..$^{[7]}$ have concluded that roughening and grooves at the surface, typically at grain corners, work as initiation spots for the shear band formation. Dao and $\mathrm{Li}^{[12]}$ concluded that a deformation texture leads to an increased roughening of the surface compared to a random texture. Kuroda and Tvergaard,${ }^{[14]}$ in their simulations, have systematically investigated how the different texture components influence the surface roughening and shear band formation. Especially, the texture components $\mathrm{Bs}$, Goss, and $\mathrm{S}$, i.e., typical 

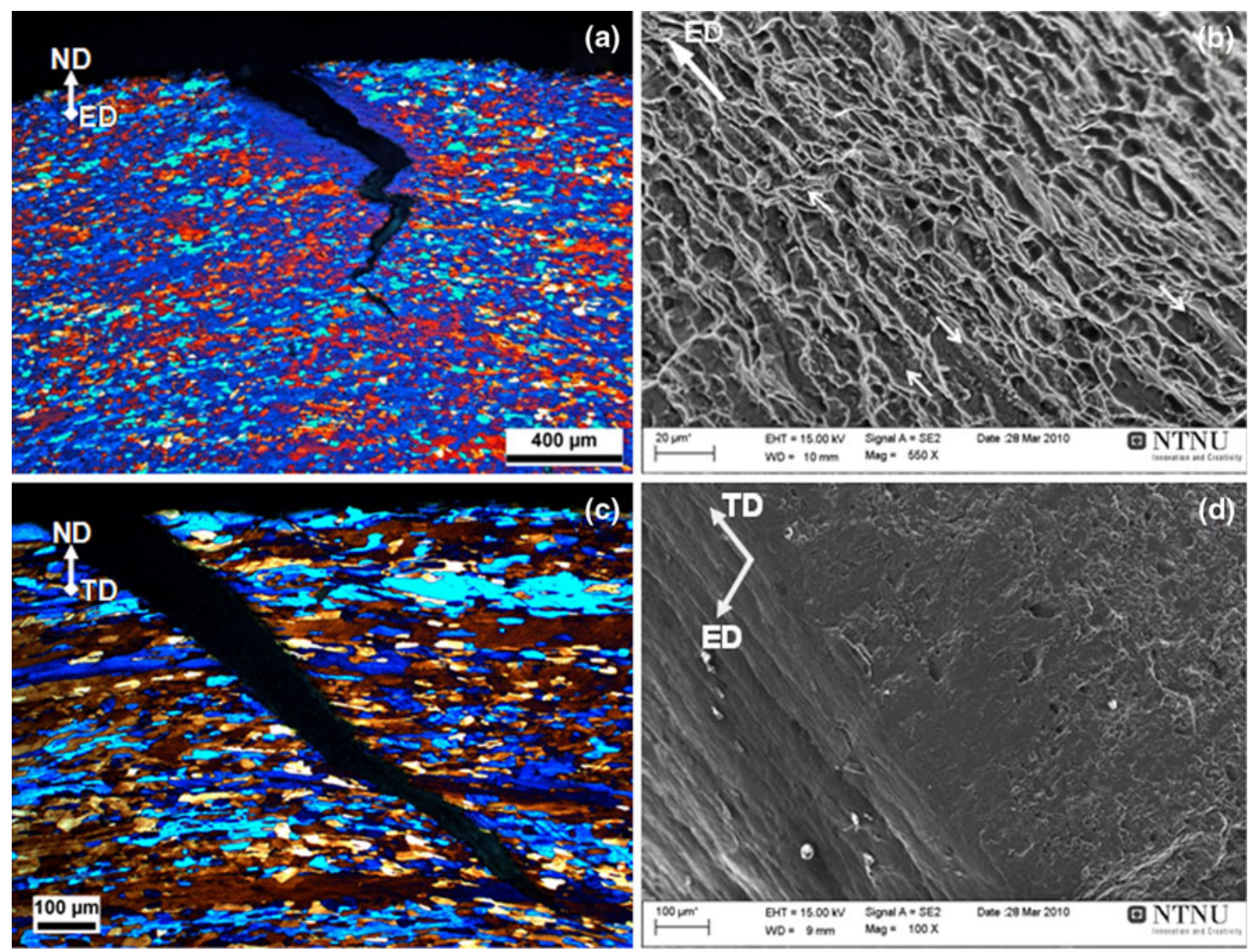

Fig. 13 - (a) through (d) Optical micrographs and SEM images of the fracture surface of the recrystallized material aged to the $5 \mathrm{~h}$ temper. The BA was aligned along the ED in (a) and (b) and along the TD in (c) and (d). The arrows in (b) indicate stringers of particles aligned along the ED.
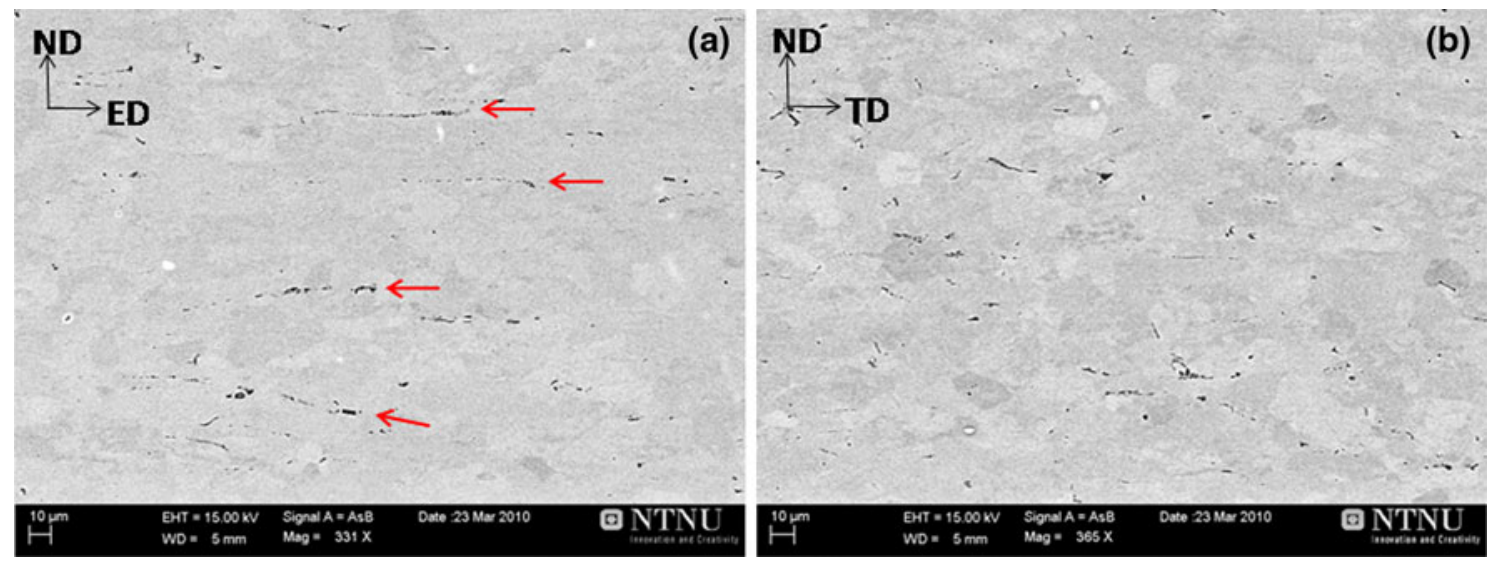

Fig. 14-Particle distribution in the recrystallized material in $(a)$ the ED-ND plane and $(b)$ the TD-ND plane.

deformation texture components, seem to promote the formation of shear bands independent of the direction of BA. This was found not only on the tension side, but also on the compression side of the samples in threepoint bending, especially pronounced with the BA aligned with the rolling direction. This is consistent with the observation in Figures 10(a) and (c), where intense shear bands are seen on the compression side of the extruded material, where we have a strong deformation texture ( $c f$. Figure 5(a)). This phenomenon is not observed for the recrystallized material, where the observed texture is very weak and closer to a random texture. In the simulations by Kuroda and Tvergaard, ${ }^{[14]}$ a random texture revealed a much more homogenous 


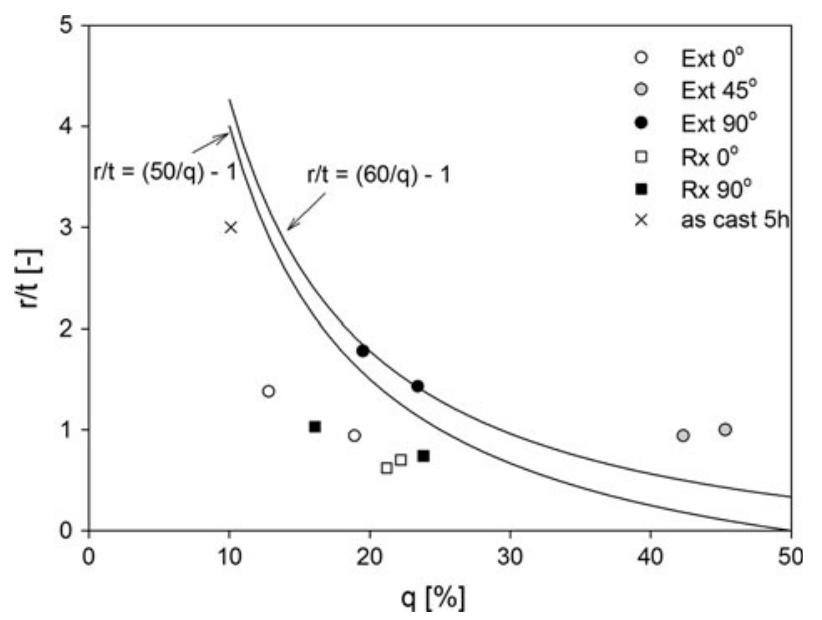

Fig. 15-The bendability $(r / t)$ plotted $v s$ the reduction in area, $q$. The orientations refer to the directions in uniaxial tension. The full lines are the empirical relations suggested by Datsko and Yang. ${ }^{[1]}$

deformation to larger strains compared to the fiber texture components. This is supported by the observations of the present work.

Apparently, the texture seems to influence the bendability of the alloy by initiation of shear bands. From the normalized force-displacement curves in Figure 8, the strong anisotropy effect regarding the extruded material is easily observed in the difference in normalized force, depending on the direction of the BA. When the BA is aligned with the ED ( $0 \mathrm{deg})$ and $45 \mathrm{deg}$ to the ED, the normalized force is approximately 10 pct higher compared to the normalized force when the BA is aligned along the TD (90 deg). This force anisotropy may be explained as an effect of the crystallographic texture. The recrystallized material, with a weaker texture, does not show any direction dependence regarding the normalized force. Interestingly, there is still a large difference in the obtained displacement dependent on the alignment of the BA. The observed anisotropy in bending angle, therefore, cannot be attributed to texture alone. A possible explanation is the alignment of primary particles during deformation. In the rolling or extrusion process, the primary particles are smeared out in the deformation direction and end up like beads on a string ( $c f$. Figure 14(a)). The alignment of the particles remains unaltered by recrystallization and is, therefore, a common phenomenon in both the fibrous and recrystallized materials. When the BA is aligned with the ED, the strings of particles run parallel with the BA. From the fracture investigation in Figure 13(b), the strings are clearly seen on the fracture surface. Decohesion, void growth, and coalescence are most likely to occur along the strings, increasing the stress in the regions in between. This makes it easier for the crack to follow a path that goes from string to string, leaving the characteristic zigzag crack growth. In the case where the $\mathrm{BA}$ is aligned with TD, the strings of particles, on the other hand, are perpendicular to the $\mathrm{BA}$, i.e., aligned parallel with the deformation direction, and do not affect the fracture propagation in the same way. When the shear bands are formed, most of the deformation is localized in the bands; i.e., in this case, ductile fracture occurs directly in the bands.

\section{CONCLUSIONS}

Three-point plane-strain bending tests were carried out on two tempers of an AA7108 alloy with three different microstructures: as-cast and homogenized material, fibrous extruded material, and cold rolled and recrystallized material. Despite a similar strength in tension, the three materials reveal a large variation in bendability. The as-cast and homogenized material performs extremely poorly in three-point bending. This is most probably due to the nature of the as-cast microstructure, with large grains and constituent particles aligned on the grain boundaries and in the dendritic as-cast structure. This causes a combination of intercrystalline and transcrystalline fracture along the path with the highest density of particles. Both of the two predeformed materials show anisotropic behavior in three-point bending, with a better bendability when the BA is aligned with the TD. The extruded material with a strong fiber texture shows an anisotropic behavior both in tension and bending tests with respect to the normalized force. The cold rolled and recrystallized material with a very weak texture, on the other hand, exhibits a nearly isotropic behavior. Shear band formation was found to be the major failure initiation mechanism and is influenced by texture. Investigations of the crack propagation, however, show that the reason for the difference in bendability should be found in the alignment of primary particles along the deformation direction.

\section{OPEN ACCESS}

This article is distributed under the terms of the Creative Commons Attribution Noncommercial License which permits any noncommercial use, distribution, and reproduction in any medium, provided the original author(s) and source are credited.

\section{REFERENCES}

1. J. Datsko and C.T. Yang: J. Eng. For Ind. B, 1960, vol. 82, pp. $309-14$.

2. C. Wang, D. Kinzel, and T. Altan: J. Mater. Process. Technol., 1993, vol. 39, pp. 279-304.

3. R. Akeret: Aluminium, 1978, vol. 54, pp. 117-23.

4. C. Iacono, J. Sinke, and R. Benedictus: J. Manufact. Sci. Eng., 2010, vol. 132, pp. 1-9.

5. J. Kang, D.S. Wilkinson, D.V. Malakhov, H. Halim, M. Jain, J.D. Embury, and R.K. Mishra: Mater. Sci. Eng. A, 2007, vol. 456, pp. 85-97.

6. T. Minoda, M. Asano, and H. Yoshida: Mater. Sci. Forum, 2006, vols. 519-521, pp. 859-64.

7. J. Sarkar, T.R.G. Kutty, D.S. Wilkinson, J.D. Embury, and D.J. Lloyd: Mater. Sci. Eng. A, 2004, vol. 369, pp. 258-66.

8. J. Sarkar, T.R.G. Kutty, K.T. Conlon, D.S. Wilkinson, J.D. Embury, and D.J. Lloyd: Mater. Sci. Eng. A, 2001, vol. 316, pp. $52-59$. 
9. A.R. Ragab and C.A. Saleh: Mater. Sci. Eng. A, 2005, vol. 395, pp. 102-09.

10. M.B. Bettaieb, X. Lemoine, L. Duchêne, and A.M. Habraken: Mater. Sci. Eng. A, 2010, vol. 528, pp. 442-48.

11. M.B. Bettaieb, X. Lemoine, L. Duchêne, and A.M. Habraken: Mater. Sci. Eng. A, 2010, vol. 528, pp. 434-41.

12. M. Dao and M. Li: Phil. Mag. A, 2001, vol. 81, pp. 1997-2020.

13. D.S. Wilkinson, X. Duan, J. Kang, M. Jain, and J.D. Embury: Mater. Sci. Forum, 2006, vols. 519-521, pp. 183-90.

14. M. Kuroda and V. Tvergaard: Int. J. Plast., 2007, vol. 23, pp. 244-72.

15. M. Kuroda and V. Tvergaard: Eur. J. Mech. A/Sol., 2004, vol. 23, pp. 811-21.
16. R. Becker: J. Appl. Mech., 1992, vol. 59, pp. 491-96.

17. W.Y. Chien, J. Pan, and S.C. Tang: Int. J. Plast., 2004, vol. 20, pp. 1953-81.

18. K.E. Snilsberg, I. Westermann, B. Holmedal, O.S. Hopperstad, Y. Langsrud, and K. Marthinsen: Mater. Sci. Forum, 2009, vols. 638642, pp. 487-92.

19. H. Bold: "Plättchen-Biegeversuch," PAPP PWT 4108, Daimler Chrysler, Sindelfingen, Germany, Feb. 2004.

20. D. Dumont, A. Deschamps, and Y. Bréchet: Mater. Sci. Eng. A, 2003, vol. 356, pp. 326-36.

21. D. Dumont, A. Deschamps, and Y. Bréchet: Acta Mater., 2004, vol. 52 , pp. 2529-40. 